\title{
BASES PARA UMA TEORIA GERAL DAS CONSTRUÇÕES FORMAIS
}

Bases for a general theory of formal constructions

Fábio Salgado de Carvalho*

Resumo: O termo "formalização" tem sido utilizado de maneira pouco precisa na área filosófica. Há certo fetiche pelos formalismos, especialmente na filosofia analítica, mas não há uma compreensão, de fato, do que eles são. Que é uma formalização? Uma metodologia? Um estilo filosófico? Ela confunde-se com a mera "matematização"? É uma representação simbólica? É o abarcamento por um sistema lógico? Há diferenças entre modelar um conceito, uma inferência ou uma teoria e formalizá-los? O que é objeto de uma formalização? A partir de uma conceituação clara, quais seriam as vantagens e desvantagens do seu uso na Filosofia? Buscaremos fornecer, neste trabalho, as bases para uma teoria geral das formalizações assim como princípios condutores para os filósofos que desejam criar e propor formalizações.

Palavras-chave: Formalização. Linguagens formais. Sistemas lógicos. Lógica formal.

\begin{abstract}
The term "formalization" has been used in the area of philosophy in a less than precise manner. There exists a certain fetish regarding formalisms, especially in Analytic Philosophy, but in fact no understanding of what they are. What is a formalization? A methodology? A philosophical style? Is it indistinguishable from mere "mathematization"? Is it a symbolic representation? Is it the simple fact of being embraced by a logical system? Are there diferences between modelling a concept, an inference or a theory, and formalizing them? What is the object of a formalization? If we begin with a clear conceptualization of it, what would be the advantages and disadvantages of its use in philosophy? In the present essay, we shall endeavor to provide the bases for a general theory of formalizations, along with the guiding principles for philosophers who wish to create and propose them.
\end{abstract}

Keywords: Formalization. Formal languages. Logical systems. Formal logic.

* Mestrando em Filosofia na Universidade de Brasília (UnB), bolsista da CAPES - E-mail: fabiosalgado@gmail.com

\begin{tabular}{|c|c|l|l|l|l|}
\hline intuitio & $\begin{array}{c}\text { ISSN } \\
1983-4012\end{array}$ & Porto Alegre & Vol.9- $\mathrm{N}^{\mathrm{o} .1}$ & $\begin{array}{l}\text { Julho } \\
2016\end{array}$ & p.15-27 \\
\hline
\end{tabular}




\section{Introdução}

A silogística aristotélica costumava ser considerada como sendo a primeira abordagem formal da Lógica. A abordagem dos estóicos tem sido considerada formal na medida em que eles lidavam com variáveis, escrevendo "o primeiro", "o segundo" ou "o terceiro" para lidar com estruturas em vez de conteúdos $^{1}$. Sabe-se hoje, entretanto, que foi o chinês Mozi, ou Mestre Mo, na Escola Moísta, que foi influente entre 479 e 221 antes de Cristo, o primeiro a abordar a Lógica de maneira formal ${ }^{2}$. A razão pela qual os desenvolvimentos lógicos de Mozi são vistos como sendo os primeiros formalistas é, precisamente, pelo uso de variáveis - pensando aqui em termos da representação costumeira feita na lógica proposicional - e de esquemas de fórmulas. Podemos, portanto, já destacar um critério necessário, mas não suficiente, para a formalização, que seria o uso de variáveis.

Uma consulta ao The Cambridge Dictionary of Philosophy ${ }^{3}$ diz-nos que uma formalização é uma representação abstrata. Por vezes, a Lógica Formal é vista como um campo que lida com estruturas em detrimento de conteúdos - aqui, temos a abstração envolvida nas formalizações. Esta visão é vaga, pois o que é visto como estrutural e como conteudístico tem mudado com o decorrer do tempo. A título de exemplo, podemos mencionar uma crítica que sempre tem sido dirigida à Lógica Formal, principalmente por aqueles que não estão atualizados com os últimos avanços da Lógica contemporânea. Os avessos à Lógica Formal dizem, em certas ocasiões, que ela é incapaz de lidar com o dinamismo e que é, por conseguinte, estática ${ }^{4}$. Sabemos, entretanto, com as lógicas temporais, que conceitos temporais podem ser internalizados em uma dada lógica. De fato, na lógica proposicional clássica, ou mesmo na lógica de primeira ordem, não se diferenciam frases em tempos verbais distintos, mas esta distinção pode ser caracterizada em um sistema formal.

Miguel Reale ${ }^{5}$ dizia que "as palavras guardam o segredo do seu significado". A palavra portuguesa "forma" tem a sua raiz no Latim - a palavra "formalização" foi introduzida na Língua Portuguesa via Francês. As acepções do termo latino são muitas para que tivéssemos alguma pretensão de, por meio de um exame apurado, descobrir o que estamos falando quando fazemos menção à formalização. Tampouco, parece-nos que analisar o hilemorfismo aristotélico ou a Teoria das Formas platônica poderia oferecer-nos algum esclarecimento acerca da questão.

\footnotetext{
${ }^{1}$ LONG, A. A.; SEDLEY, D. N. The hellenistic philosophers. Great Britain: Cambridge University Press, 1987.

${ }^{2}$ ZHANG, J.; LIU, F. Some Thoughts on Mohist Logic. In: A Meeting of the Minds: Proceedings of the Workshop on Logic, Rationality and Interaction, Johan van Benthem, Shier Ju and Frank Veltman (eds.), London: College Publications, 85-1, 2007

${ }^{3}$ AUDI, R. The Cambridge Dictionary of Philosophy. United Kingdom: Cambridge university press, 1999.

${ }^{4} \mathrm{Na}$ verdade, há quem defenda que mesmo as lógicas temporais são incapazes de abarcar a dinâmica do pensamento.

${ }^{5}$ REALE, M. Lições Preliminares de Direito. $27^{\mathrm{a}}$ edição. São Paulo: Saraiva, 2002, p.4.
}

\begin{tabular}{|c|c|l|l|l|l|}
\hline intuitio & $\begin{array}{c}\text { ISSN } \\
1983-4012\end{array}$ & Porto Alegre & Vol.9- $\mathrm{N}^{\mathrm{o}} .1$ & $\begin{array}{l}\text { Julho } \\
2016\end{array}$ & p.15-27 \\
\hline
\end{tabular}


Uma consulta ao dicionário Houaiss dá-nos a seguinte definição para a palavra: "procedimento por meio do qual um sistema de conhecimentos é considerado em suas estruturas formais, por meio de símbolos algébricos, axiomas, normas sintáticas e desenvolvimentos lógicos, e assim purificado de seus conteúdos empíricos ou materiais".

No contexto do Programa de Hilbert ${ }^{6}$, de fato, uma formalização era entendida em termos de sistemas axiomáticos. Não nos parece, entretanto, que a geometria de Euclides fosse formal por fazer uso de axiomas ou que um sistema lógico que não faça uso de axiomas deixe de ser formal por isso voltaremos a essa discussão adiante.

Leônidas Hegenberg ${ }^{7}$, no seu Dicionário de Lógica, define uma formalização da seguinte maneira: "Chama-se formalização a elaboração de um sistema logístico ${ }^{8}$ para o qual a interpretação pretendida transforme verdades (de um dado assunto sob exame) em teoremas do sistema". Por "sistema logístico", Hegenberg ${ }^{9}$ entende que seja "qualquer sistema cujos elementos primitivos (termos, regras de formação, axiomas e regras de inferência) estão explicitamente formulados na metalíngua".

Primeiramente, cabe-nos ressaltar que há discussões sobre o entendimento do que venha a ser um sistema lógico. Dov Gabbay ${ }^{10}$, por exemplo, editou um texto intitulado What is a logical system contendo discussões sobre o assunto. Na verdade, poderíamos perder-nos na discussão de maneira indefinida, uma vez que, muito provavelmente, o embate acerca do que venha a ser um sistema lógico envolveria discussões sobre conceitos que não são claros ou que envolvem ambigüidade. O importante na definição do Hegenberg é que vemos algo que será muito importante em uma formalização; a saber, o ambiente metalingüístico. Em segundo lugar, sabemos hoje que sistemas lógicos podem privilegiar o conceito de falsidade em detrimento do conceito de verdade ${ }^{11}$.

O The Blackwell Dictionary of Western Philosophy ${ }^{12}$ fornece a resposta para uma das questões que levantamos no resumo deste texto: o que é objeto de uma formalização? O verbete no referido dicionário diz-nos que uma formalização é a prática de criar um esquema de correspondência entre linguagem ordinária e linguagens formais. Portanto, o objeto das formalizações é a linguagem ordinária. Não faz sentido dizer que formalizaremos uma árvore ou uma pessoa, a não ser que estejamos falando em sentido figurado, dizendo que um trabalhador informal terá uma carteira de trabalho ou que um maltrapilho vestirá um fraque.

\footnotetext{
${ }^{6}$ ZACH, R. Hilbert's program. In: ZALTA, E. N. (ed.). The Stanford Encyclopedia of Philosophy. Disponível em: $<$ http://plato.stanford.edu/archives/spr2009/entries/hilbert-program/>. Acesso em 06 de jan. 2015

${ }^{7}$ HEGENBERG, L. Dicionário de Lógica. São Paulo: EPU, 1995, p.86.

8 O termo "logístico" não é corrente na literatura, sendo mais usado em áreas como a Administração ou Contabilidade.

${ }^{9}$ HEGENBERG, L. Dicionário de Lógica. São Paulo: EPU, 1995, p. 200-201.

${ }^{10}$ GABBAY, D. (ed.) What is a logical system. Oxford: Clarendon press, 1994.

${ }^{11}$ SANZ, W. Falsity preservation. CLE e-Prints (Online), v. 8, p. 2, 2008.

${ }^{12}$ BUNNIN, N.; YU, J. The Blackwell Dictionary of Western Philosophy. USA: Blackwell publishing, 2004, p.268.
}

\begin{tabular}{|c|c|c|c|c|c|}
\hline intuitio & $\begin{array}{c}\text { ISSN } \\
1983-4012\end{array}$ & Porto Alegre & Vol.9- $\mathrm{N}^{\circ} .1$ & $\begin{array}{l}\text { Julho } \\
2016\end{array}$ & p.15-27 \\
\hline
\end{tabular}


Wittgenstein influenciou duas linhas metodológicas na Filosofia Analítica. $O$ primeiro Wittgenstein influenciou o Círculo de Viena, que possuía uma abordagem formalista, enquanto o segundo Wittgenstein influenciou a Escola de Oxford, que possui uma linha metodológica baseada na linguagem ordinária. Hoje, dificilmente, um filósofo analítico trabalha com uma linha em detrimento de outra. Esse fato ocorreu, no nosso entendimento, por conta de vários acontecimentos históricos.

Richard Montague defendia que "não há nenhuma diferença essencial entre as línguas naturais e as linguagens formais" ${ }^{\prime 3}$. Chomsky, com a sua Gramática Gerativa, também deu ensejo a uma série de estudos que foram muito influentes na maneira como as linguagens formais passaram a ser encaradas. Além do mais, a semântica, que era mal vista pelos membros do Círculo de Viena — dizem que Carnap virou motivo de chacota para Neurath, por exemplo, por conta do seu trabalho em Semântica — recebeu um tratamento rigoroso com Tarski, Kripke, entre outros.

\section{Sobre o pluralismo das formalizações e o seu caráter pragmático}

É importante destacarmos o caráter pluralista das formalizações. Com pluralismo, queremos dizer que não há uma maneira unívoca de formalizar uma linguagem ordinária ou natural. Talvez essa característica leve-nos a definir as formalizações como Wittgenstein definiu os seus "jogos de linguagem", evitando fornecer características categóricas, tratando-os por meio de "semelhanças de família"; entretanto, uma das nossas propostas iniciais era a de fornecer definições claras e precisas. Cremos, portanto, que esse caráter pluralista não é um empecilho para o cumprimento da nossa proposta. Teremos de elucidar critérios de decisão para tratarmos da igualdade, e consequiente desigualdade, de formalizações. Antes disso, entretanto, recorreremos a um exemplo para mostrarmos o que queremos dizer com o "caráter pragmático" das formalizações.

Suponhamos que eu queira formalizar a frase da linguagem natural "Todo homem era mortal". Qualquer sistema lógico meramente proposicional daria uma letra, como, por exemplo, "p" para que representássemos essa frase. Um sistema de primeira ordem, por sua vez, poderia fornecer a seguinte representação simbólica: “ $\forall \mathrm{x}(\mathrm{Hx} \rightarrow \mathrm{Mx})$ ”. Poderíamos, ainda, fazer uso de um sistema temporal para captar o tempo verbal do verbo "ser" na frase. Alguém pode perguntar-se: "qual a formalização correta?". Na verdade, feita dessa maneira, a pergunta está mal colocada e explicamos o porquê.

Se é do meu interesse lidar com a frase "Todo homem era mortal" em termos mais gerais, pode ser o caso de que a formalizar simplesmente como "p" seja satisfatório. Por exemplo, se quero mostrar, simplesmente, que poderíamos deduzir dessa frase que "Sócrates era mortal", não é preciso entrar em detalhes quanto ao conteúdo da frase. Se quero, entretanto, explicitar as características de ser homem e

${ }^{13}$ PEREIRA, M. K. F. Sintaxe e semântica universais. Campinas: Unicamp, 2001, p. xiii (Coleção CLE).

\begin{tabular}{|c|c|c|c|c|c|}
\hline intuitio & $\begin{array}{c}\text { ISSN } \\
1983-4012\end{array}$ & Porto Alegre & Vol.9- No.1 & $\begin{array}{c}\text { Julho } \\
2016\end{array}$ & p.15-27 \\
\hline
\end{tabular}


de ser mortal em termos de predicados por alguma razão, não me interessando o caráter temporal da frase, contentar-me-ei com um sistema de primeira ordem, assim como um sistema temporal será necessário se preciso expressar o caráter temporal da frase.

Há hoje muitas discussões sobre o monismo ou pluralismo de sistemas lógicos. Cremos, entretanto, que a maioria dos lógicos concorda que os sistemas lógicos devem ser utilizados de acordo com a necessidade; por exemplo, não há por que usar um sistema de segunda ordem se a predicação de predicados não é importante na minha abordagem. Isso se torna mais claro ainda no uso que os cientistas da computação fazem da Lógica para resolver problemas, uma vez que os custos envolvidos costumam restringir as possibilidades de formalização.

Alguém, talvez, possa perguntar-se se, entretanto, dadas as restrições, há uma maneira unívoca de formalizar-se levando-as em consideração. A nossa resposta é positiva. Em Física e Matemática, no que concerne aos cálculos de variações, são freqüentes problemas envolvendo máximos e mínimos. Por exemplo, a catenária é a curva apresentada por um fio conectando dois pontos sob a ação da gravidade. Chamaremos de "formalização catenária" aquela que apresentar menos custos em termos de propriedades metalingüísticas. O conteúdo dessas propriedades pode fazer referência aos conceitos de Teoria da Complexidade, como, por exemplo, o menor tempo para que uma dada formalização seja rodada em algum sistema computacional ou o menor comprimento em termos de prova.

Quanto a essa otimização de uma formalização, cabe questionarmo-nos acerca da relação entre o poder expressivo de uma lógica e as suas propriedades lógicas. Seria esta relação uma relação de proporção inversa? Na Matemática, na medida em que foram desenvolvidos conjuntos algébricos, notou-se que quando se aumentava a dimensão de um conjunto perdiam-se propriedades.

Quando estendemos os Reais (R) aos Complexos (C), perdemos a comparação em termos de desigualdade entre os números: só dizemos que um complexo é menor que outro em termos da sua norma, a não ser, é claro, que a parte complexa seja nula. Quando se passa dos Complexos (C) para os Quatérnios (H), perdemos a comutatividade; quando se passa destes $(\mathrm{H})$ para os Octônios $(\mathrm{O})$, perde-se a associatividade; quando se passa destes $(\mathrm{O})$ para os Sedênios (S), perde-se a alternatividade ${ }^{14}$.

Existe um procedimento de construção dessas álgebras chamado construção de Cayley-Dickson. Talvez seja possível sabermos por que essas propriedades são perdidas por meio da avaliação do processo de construção de Cayley-Dickson. Dizemos isso porque sabemos que podemos associar a todo sistema lógico uma álgebra específica, pelo menos em princípio - ter-se-ia de ter um teorema que, de fato, demonstrasse isso; no entanto, precisaríamos de uma definição de "sistema lógico" que abarcasse todos os sistemas existentes e todos os possíveis sistemas. A perda de propriedades metalógicas de sistemas

${ }^{14}$ Essa propriedade é a seguinte: $\mathrm{x}(\mathrm{xy})=(\mathrm{xx}) \mathrm{y}$ e $(\mathrm{yx}) \mathrm{x}=\mathrm{y}(\mathrm{xx})$.

\begin{tabular}{|c|c|c|c|c|c|}
\hline intuitio & $\begin{array}{c}\text { ISSN } \\
1983-4012\end{array}$ & Porto Alegre & Vol.9- $\mathrm{N}^{\circ} .1$ & $\begin{array}{l}\text { Julho } \\
2016\end{array}$ & p.15-27 \\
\hline
\end{tabular}


que possuem maior capacidade expressiva talvez possa ser caracterizada em termos algébricos.

\section{Que são, afinal, formalizações?}

Em Teologia, freqüentemente, fala-se de abordagens catafáticas e apofáticas. No Grego, katafatikos significa "positivo", enquanto apofatikos significa "negativo". O primeiro tipo de abordagem lida, portanto, com afirmações, enquanto o segundo tipo lida com negações. Por exemplo, dizer que Deus é infinito seria um apelo ao primeiro tipo de abordagem, enquanto dizer que Deus não é mal seria um apelo ao segundo tipo.

Por vezes, parece-nos mais fácil proferir frases de teor negativo do que afirmações, embora do ponto de vista estritamente lógico frases negativas possam ser reformuladas de maneira que sejam positivas e vice-versa. Dizer, por exemplo, por que algo foi desagradável em um filme parece-nos mais fácil que dizer o que apreciamos em um filme de que gostamos muito. De maneira semelhante, parece mais fácil falar sobre as formalizações de um ponto de vista apofático do que catafático.

A fim de respondermos a algumas questões levantadas no resumo deste texto, começaremos discutindo o que as formalizações, definitivamente, não são ${ }^{15}$. Que a formalização não seja uma mera matematização parece-nos óbvio. Podemos dar alguns exemplos. A Teoria Ingênua dos Conjuntos, por exemplo, não é considerada como sendo formal. Correntemente, os matemáticos consideram a Teoria Axiomática dos Conjuntos como sendo uma formalização daquela teoria, o que não significa, como já mencionamos, que a formalização esteja restrita ao método axiomático.

De fato, tendo-se em vistas diferentes possibilidades de apresentação da teoria da prova de um sistema formal, por meio de cálculo de sequentes, por exemplo, não faria sentido restringir-nos ao método axiomático. Embora Euclides tenha construído a sua geometria por meio de axiomas, isso não foi suficiente, entretanto, para que ela fosse formal: David Hilbert, por exemplo, apresentou a geometria euclidiana em uma versão considerada formalizada.

Devemos ainda nos lembrar de que a Matemática só atingiu um nível razoável de abstração muito recentemente, principalmente com o desenvolvimento da Álgebra. Enquanto as formalizações costumam estar atreladas à abstração, nem sempre a Matemática foi desenvolvida com essa característica;

\footnotetext{
${ }^{15}$ Embora possa parecer trivial dizer o que algo não é, a despeio do fato de que se pode sempre escrever sentenças negativas em positivas e vice-versa, não é sempre trivial apontar que algo não seja outra coisa. A título de exemplo, no caso da Física, dizer no início do século XX que a luz não era uma partícula - como hoje sabemos que, de fato, ela é - era dizer muito sobre a luz. A metodologia teológica apofática não funciona, simplesmente, apontando-se casos triviais, como, por exemplo, Deus não é uma cadeira, não é uma árvore, mas foi desenvolvida, ao longo da história, toda uma técnica para fazer-se esse tipo de abordagem. A título de exemplificação, recomendamos uma consulta ao trabalho de Escoto Erígena ou de Vladimir Lossky. O Budismo e o Hinduísmo também desenvolveram metodologias negativas ou apofáticas.
}

\begin{tabular}{|c|c|c|c|c|c|}
\hline intuitio & $\begin{array}{c}\text { ISSN } \\
1983-4012\end{array}$ & Porto Alegre & Vol.9- $\mathrm{N}^{\circ} .1$ & $\begin{array}{l}\text { Julho } \\
2016\end{array}$ & p.15-27 \\
\hline
\end{tabular}


pelo contrário, durante anos os matemáticos tiveram dificuldades para lidar com entidades como o zero, o nada, a noção de infinito e assim por diante.

As formalizações não podem reduzir-se à representação simbólica: do contrário, hieroglifos seriam formalizações, o que creio que ninguém em sã consciência estaria disposto a aceitar. É importante ressaltar que o argumento aqui pode aparentar um tipo de argumentum ad consequentiam; entretanto, no tocante aos argumentos falaciosos, temos de fazer duas intervenções.

Primeiramente, sabe-se hoje, após inúmeros trabalhos em Lógica Informal, que sempre se deve levar em conta o contexto para que se possa atribuir a falaciloqüência a argumentos; segundamente, o apelo às conseqüências é falacioso quando se quer dizer que o valor de verdade de um argumento é afetado pelas suas conseqüências, enquanto o que fizemos aqui foi meramente apontar que pressupor algo levaria a uma conseqüência indesejada.

Quanto às distinções entre modelar e formalizar, podemos pensar a partir de uma área particular da ciência como a Física. Quando dizemos, neste campo do conhecimento, que temos a pretensão de modelar um evento físico, e aqui já encontramos uma diferença com a formalização no que tange ao seu objeto, estamos falando da tradução deste evento em equações matemáticas, lembrando que já discutimos que a matematização não se iguala à formalização e lembrando que as teorias físicas, em geral, não estão construídas em sistemas lógicos claramente detectáveis, o que nos leva, inclusive, a discussões em Filosofia da Ciência sobre a axiomatização da Física, o que seria um tipo particular de formalização da área.

Ionescu e Botta $^{16}$ respondem à questão de maneira que nos parece satisfatória. Eles citam um experimento mental em um texto de Shakespeare, a saber A tragédia do Rei Ricardo II, Ato V, Cena V, no qual o rei Ricardo compara a sua "angustiosa prisão" ao vasto mundo. A partir da sua condição, ele reflete sobre a condição humana em geral, assim como a partir de um evento físico particular um físico escreve equações com pretensões de descrição de fenômenos físicos que não estejam restritos apenas ao experimento realizado, abrangendo todos os tempos e todos os espaços. Em outras palavras, experimentos mentais podem ser modelos; no entanto, podem não ser formalizações.

Até aqui adotamos uma perspectiva apofática sobre o que seriam as formalizações. Adotaremos, agora, a perspectiva catafática.

Uma formalização pode ser entendida como uma função que tem por domínio objetos da linguagem natural ou ordinária e que tem por contradomínio objetos formais. Cabe-nos, entretanto, questionar-nos acerca das características dessa função. Seria essa função injetiva, ou seja, dois elementos

${ }^{16}$ IONESCU, C; BOTTA, N. Proceedings of the Dahlem Conference "Is there a mathematics of social entities?". Dec. 14-19, 2008.

\begin{tabular}{|c|c|l|l|l|l|}
\hline intuitio & $\begin{array}{c}\text { ISSN } \\
1983-4012\end{array}$ & Porto Alegre & Vol.9- $\mathrm{N}^{\circ} .1$ & $\begin{array}{l}\text { Julho } \\
2016\end{array}$ & p.15-27 \\
\hline
\end{tabular}


distintos do domínio sempre correspondem a elementos distintos do contradomínio? Cremos que não.

Bertrand Russell, a partir do seu tratamento das descrições definidas, lidou com os conceitos de forma gramatical e de forma lógica de expressões da linguagem. Montague dizia que a principal diferença entre linguagens naturais e linguagens formais está no fato de que aquelas apresentam ambigüidades, enquanto estas estão isentas de polissemias. Alguém poderia objetar dizendo que a negação, por exemplo, no âmbito formal, costuma ser entendida de diversas maneiras; entretanto, poderíamos dizer que sistemas distintos possuem entendimentos distintos e não que em um mesmo sistema a negação tenha vários significados.

Enfim, o que queremos dizer ao trazer à tona a distinção de Russell e o apontamento de Montague é que duas sentenças distintas na linguagem natural podem ter o mesmo significado; portanto, objetos diferentes do nosso domínio podem apresentar a mesma forma lógica e, portanto, o mesmo objeto no contradomínio. Talvez alguém possa sugerir que isso seria resolvido se lidássemos com as referências das sentenças em linguagem natural, mas cremos que, fazendo isso, teríamos já ultrapassado o âmbito da não-formalidade.

Ainda, no tocante às características dessa função, poderíamos questionar-nos se ela é sobrejetora, ou seja, se qualquer elemento do contradomínio é imagem de pelo menos um elemento do domínio. Em outras palavras, não existe nenhum elemento do contradomínio, constituído por objetos formais, que não esteja vinculado a um objeto da linguagem natural. Na verdade, esse questionamento levar-nos-ia ao âmbito da Metafísica.

Se defendêssemos um espelhamento do mundo aparente ao de Wittgenstein, por exemplo, teríamos a crença de que o ambiente da formalidade tem de corresponder aos objetos da linguagem natural. Cremos, entretanto, que podemos defender a sobrejeção dessa função sem termos de apelar a teses fortes de metafísica. Sabemos, de fato, que qualquer símbolo formal pode ser lido de alguma maneira. Quando nos reportamos aos objetos do nosso contradomínio, fazêmo-lo por meio da linguagem natural. Isso é um indício de que qualquer objeto do nosso contradomínio está atrelado a, pelo menos, um objeto do nosso domínio.

A formalização, portanto, poderia ser definida como uma função sobrejetiva que tem por domínio objetos da linguagem natural ou ordinária e que tem por contradomínio objetos formais. Temos, entretanto, de introduzir critérios para que possamos falar da igualdade de duas formalizações, uma vez que a mera observação do domínio e do contradomínio não seria suficiente. Deixaríamos de captar informações que nos parecem ser essenciais.

Por exemplo, o contradomínio de uma formalização que apele à lógica clássica que faça uso da notação de Frege e aquele de outra formalização que faça uso da notação polonesa, também na lógica clássica, seriam distintos? Uma lógica que usasse letras do alfabeto latino para representar variáveis

\begin{tabular}{|c|c|c|c|c|c|}
\hline intuitio & $\begin{array}{c}\text { ISSN } \\
1983-4012\end{array}$ & Porto Alegre & Vol.9- $\mathrm{N}^{\mathrm{o}} .1$ & $\begin{array}{l}\text { Julho } \\
2016\end{array}$ & p. $15-27$ \\
\hline
\end{tabular}


proposicionais e outra que fizesse uso do alfabeto cirílico seriam distintas?

Introduziremos critérios para identificarmos quando duas formalizações serão iguais. $\mathrm{O}$ termo "igualdade" talvez seja inadequado de maneira que adotaremos o termo "isomorfismo" no sentido de que trabalhar com formalizações isomorfas seria o mesmo. É importante ressaltar aqui que estamos evitando construir uma formalização das formalizações, o que acreditamos ser circular em termos de uma justificação para elas.

O domínio e o contradomínio da função de formalização, que chamaremos de $F$ daqui em diante, abarcam, na verdade, fragmentos da linguagem natural e fragmentos da linguagem formal. $\mathrm{O}$ primeiro critério, portanto, para que duas formalizações sejam iguais é que haja não apenas uma bijeção entre os respectivos domínios e contradomínios, mas que essa bijeção abarque as referências dos objetos desses conjuntos.

Tendo em vista a noção de formalização catenária que introduzimos, um segundo critério de igualdade para as formalizações é que elas tenham as mesmas propriedades metalógicas, ou seja, se uma formalização $F 1$ for completa — de modo que o sistema formal atrelado à formalização seja completo —, a formalização isomorfa $F_{2}$ deve ser, também, completa. Pode-se perceber, portanto, que a caracterização da linguagem nas formalizações não é relevante para o nosso critério.

\section{Vantagens e desvantagens das formalizações}

O que dissemos sobre a visão de Montague acerca das linguagens naturais e das formais já nos dá uma dica de pelo menos uma vantagem na utilização de linguagens formais; a saber, falamos da eliminação de ambigüidade. Entretanto, devido ao caráter pragmático que já salientamos anteriormente, essa vantagem pode tornar-se uma desvantagem em certos contextos. A título de exemplo, em contextos poéticos, não parece ser desvantajoso que se trabalhe com ambigüidades. Há muitas metodologias filosóficas ao alcance do filósofo e nem todas elas têm a mesma visão com relação à prática filosófica. Dificilmente, por exemplo, imaginaríamos Heidegger fazendo uso do aparato lógico desenvolvido no século XX para filosofar por conta das suas convicções metodológicas, assim como dificilmente imaginaríamos Carnap utilizando um linguajar mais poético em detrimento do rigor das linguagens formais. A despeito de convicções metafilosóficas, a linguagem clara e precisa pode ser extremamente desvantajosa quando se busca a promoção de um suposto pensamento profundo em detrimento da busca sincera pelo conhecimento. Linguagens formais facilitam a refutação, enquanto as linguagens naturais, pela sua riqueza, sempre facilitam interpretações que evitem o contraditório.

Uma segunda vantagem a ser citada é o fato de que as linguagens formais estão, de certa maneira, sob nosso controle. Podemos criar linguagens formais novas na medida das nossas

\begin{tabular}{|c|c|l|l|l|l|}
\hline intuitio & $\begin{array}{c}\text { ISSN } \\
1983-4012\end{array}$ & Porto Alegre & Vol.9- $\mathrm{N}^{\mathrm{o}} .1$ & $\begin{array}{l}\text { Julho } \\
2016\end{array}$ & p.15-27 \\
\hline
\end{tabular}


necessidades, enquanto não somos donos exclusivos da língua natural.

Certos lingüistas dizem que não somos meros usuários das linguagens naturais; cremos, entretanto, que o fato de que não nascemos falantes da nossa língua materna, tendo de aprender a sua estrutura com o passar do tempo, é um forte indício de que não estamos lidando com algo que nos pertence, embora, com o passar do tempo, o falante possa, de fato, apropriar-se de certas estruturas e fazer opções. Seria, contudo, problemático afirmarmos que esse falante não está fazendo uso de uma estrutura própria que lhe pertence, mas que continua a utilizar a língua materna que aprendeu.

A formalização, ainda, tem um papel que parece ser muito favorável a ela em tempos em que se fala tanto de intedisciplinaridade. Hoje, temos diversos métodos de combinação de lógicas que nos permitem trabalhar com conceitos que, aparentemente, não teriam interações entre si. Um dos grandes projetos da Física contemporânea, por exemplo, que é o intuito de unificar as duas grandes teorias físicas Relatividade Geral e Mecânica Quântica - tem sido visto por alguns lógicos como sendo um projeto a ser realizado por meio da adoção de um sistema lógico diferente do sistema clássico. O ambiente da formalização, portanto, permite uma visão global e unificada de teorias que pareçam ser incompatíveis.

Outra vantagem que poderíamos citar é referente ao fato de que as linguagens formais dão-nos a possibilidade de resolver problemas. Russell, por exemplo, resolveu a questão da referência de expressões da linguagem natural que fazem uso de descrições definidas, assim como solucionou paradoxos por meio da sua Teoria dos Tipos. Não são raras as soluções de problemas filosóficos que recorrem ao uso de ferramentas formais.

Quanto às desvantagens, cremos que, para falarmos de maneira satisfatória delas, teríamos de ter uma teoria razoável acerca das lógicas, na linha do que Jean-Yves Béziau ${ }^{17}$ propôs. Dizemos isso porque durante muito tempo as críticas às formalizações estavam restritas às propriedades de sistemas lógicos particulares. Já mencionamos, por exemplo, a crítica concernente a uma suposta falta de dinamicidade das estruturas formais. A nossa crença é a de que, se não forem feitas certas restrições com relação às propriedades metalógicas, sempre será possível construir um sistema formal que consiga modelar o que um dado sistema foi incapaz de fazer.

Hoje, as propriedades metalógicas que parecem ser mais razoáveis de serem cobradas em um sistema é que ele seja correto e completo; entretanto, até pouco tempo, a consistência ocupava essa posição. Não há como saber se a correção e a completude serão no futuro as propriedades mais esperadas em um sistema para que ele pareça ser razoável. O leitor pode ficar espantado com o nosso despudor em fornecer vantagens sem ter essa teoria universal sobre as lógicas em face da nossa timidez em apresentar desvantagens.

${ }^{17}$ BÉZIAU, J-Y. Universal Logic. Logica ‘94. P. Kolar et V. Svoboda (eds.), Académie des Sciences, Prague, p. 73-93, 1994.

\begin{tabular}{|c|c|c|c|c|c|}
\hline intuitio & $\begin{array}{c}\text { ISSN } \\
1983-4012 \\
\end{array}$ & Porto Alegre & Vol. $9-\mathrm{N}^{\mathrm{o}} .1$ & $\begin{array}{l}\text { Julho } \\
2016 \\
\end{array}$ & p. $15-27$ \\
\hline
\end{tabular}


Lembremo-nos, no entanto, do nosso velho Aristóteles. Para que eu diga que algo tem uma vantagem, preciso apresentar pelo menos um exemplo, portanto, tendo apenas um sistema lógico em vista, posso apresentar uma vantagem da formalização, mesmo que todas as outras abordagens venham a ser insatisfatórias. Para, por sua vez, dizer que a formalização possui alguma desvantagem, é necessário que eu conheça todas as formalizações possíveis para que eu diga que, de fato, há alguma desvantagem. Portanto, dizemos que apresentar as vantagens das formalizações é uma trivialidade, enquanto apresentar as suas desvantagens é uma impossibilidade, pelo menos a partir do que temos de mais avançado sobre o tratamento da Lógica.

\section{A Conjectura da não-coincidência de linguagens}

Tendo-se por base a importância do âmbito metalingüístico para as formalizações, devemos lembrar-nos de que Gödel, em 1931, provou o seu resultado "sobre as proposições indecidíveis do Principia Mathematica e sistemas aparentados"18. A formulação do resultado do que ficou conhecido por "Teorema de Gödel”, em linhas gerais, é a seguinte:

I - Se S é um sistema formal suficientemente forte para conter a aritmética elementar, então S é inconsistente ou incompleto;

II - A eventual consistência de um tal sistema formal não pode ser provada apenas com os recursos daquele mesmo sistema (isto é: ela tem de ser provada num sistema mais forte do que $\mathrm{S}$ ).

A partir dos teoremas de Gödel, vemos que é necessário um sistema mais forte que aquele que contenha a aritmética elementar para mostrar a consistência desse sistema. Ora, um sistema lógico clássico de ordem zero é mais fraco que um sistema de primeira ordem; portanto, Gödel não está falando de sistemas diferentes em termos de serem clássicos ou não, mas apenas em termos de capacidade expressiva para aplicação de predicações.

A nossa conjectura é a de que, dado um sistema formal, a sua metalinguagem não deve coincidir com a linguagem utilizada na linguagem-objeto, ou seja, se um sistema é clássico, a sua metalinguagem não deve ser clássica. Ou se uma linguagem-objeto é não-clássica, a sua metalinguagem deve ser clássica ou outra não-clássica que não coincida com aquela que foi utilizada anteriormente na caracterização da linguagem-objeto.

É importante destacar que se esta conjectura for verdadeira, a tese da pluralidade de lógicas estará automaticamente demonstrada como corolário, enquanto a sua falsidade mostraria apenas o que chamamos de um monismo fraco, que seria a completa dependência de um tipo de caracterização sistemática uma vez que se escolha um dado sistema.

\footnotetext{
${ }^{18}$ Fazemos uso, aqui, da apostila inédita de GOMES.
}

\begin{tabular}{|c|c|c|c|c|c|}
\hline intuitio & $\begin{array}{c}\text { ISSN } \\
1983-4012\end{array}$ & Porto Alegre & Vol.9- $\mathrm{N}^{\mathrm{o} .1}$ & $\begin{array}{l}\text { Julho } \\
2016\end{array}$ & p.15-27 \\
\hline
\end{tabular}




\section{Conclusão}

Neste trabalho, respondemos às questões inicialmente levantadas sobre o que seria uma formalização. Por meio de uma abordagem positiva e outra negativa, buscamos responder o que a formalização não seria, mas, também, o que ela viria a ser.

Introduzimos o conceito de formalização catenária para lidarmos com a formalização que envolveria menos custos em termos pragmáticos, ou seja, em termos do que o formalizador em questão gostaria que fosse otimizado em termos de propriedades metalógicas.

Apresentamos uma definição da formalização, a partir da abordagem de funções, indicando que a formalização seria uma função que não seria injetiva, mas sobrejetora, conectando um conjunto de objetos da linguagem natural ou ordinal a um conjunto de objetos formais.

Fizemos uma discussão acerca das vantagens e desvantagens das formalizações, de maneira que mostramos a impossibilidade de falar-se de desvantagens em termos gerais, uma vez que não temos uma caracterização universal que seja satisfatória dos sistemas lógicos. No tocante às vantagens, podemos enumerá-las:

$$
\begin{gathered}
1 \text { - eliminação de ambigüidades; } \\
2 \text { - maior controle na manipulação da linguagem; } \\
3 \text { - facilitação da interdisciplinaridade; } \\
4 \text { - resolução de problemas. }
\end{gathered}
$$

Apresentamos, ao final, uma conjectura referente ao campo da metalinguagem, aproveitando a nossa discussão acerca do pluralismo de formalizações baseado em contextos pragmáticos, uma vez que um mesmo objeto da linguagem natural pode ser formalizado de muitas maneiras. O presente texto, entretanto, não esgota o assunto de maneira alguma; ao contrário, fornece diversas ferramentas para uma discussão mais proveitosa acerca das formalizações.

\section{Referências}

AUDI, R. The Cambridge Dictionary of Philosophy. United Kingdom: Cambridge university press, 1999.

BÉZIAU, J-Y. Universal Logic. Logica '94. P. Kolar et V. Svoboda (eds.), Académie des Sciences, Prague, p. 73-93, 1994.

BUNNIN, N.; YU, J. The Blackwell Dictionary of Western Philosophy. USA: Blackwell publishing, 2004. http://dx.doi.org/10.1111/b.9781405106795.2004.x

http://dx.doi.org/10.1002/9780470996379

COSTA-LEITE, A. Construções sistêmicas e leis de interação. Cognitio. São Paulo, vol. 10, n.2, p. 209-220, jul./dez. 2009.

GABBAY, D. (ed.) What is a logical system. Oxford: Clarendon press, 1994.

GOMES, N. G. Lógica Modal (Apostila)

\begin{tabular}{|c|c|c|c|c|c|}
\hline intuitio & $\begin{array}{c}\text { ISSN } \\
1983-4012\end{array}$ & Porto Alegre & Vol.9- $\mathrm{N}^{\circ} .1$ & $\begin{array}{l}\text { Julho } \\
2016\end{array}$ & p.15-27 \\
\hline
\end{tabular}


HEGENBERG, L. Dicionário de Lógica. São Paulo: EPU, 1995.

IONESCU, C; BOTTA, N. Proceedings of the Dahlem Conference "Is there a mathematics of social entities?". Dec. 14-19, 2008.

LONG, A. A.; SEDLEY, D. N. The hellenistic philosophers. Great Britain: Cambridge University Press, 1987.

http://dx.doi.org/10.1017/CBO9780511808050

http://dx.doi.org/10.1017/CBO9781139165907

PEREIRA, M. K. F. Sintaxe e semântica universais. Campinas: Unicamp, 2001. (Coleção CLE)

REALE, M. Lições Preliminares de Direito. 27a edição. São Paulo: Saraiva, 2002.

SANZ, W. Falsity preservation. CLE e-Prints (Online), v. 8, p. 2, 2008.

ZACH, R. Hilbert's program. In: ZALTA, E. N. (ed.). The Stanford Encyclopedia of Philosophy. Disponível em: <http://plato.stanford.edu/archives/spr2009/entries/hilbert-program/>. Acesso em 06 de jan. 2015.

ZHANG, J.; LIU, F. Some Thoughts on Mohist Logic. In: A Meeting of the Minds: Proceedings of the Workshop on Logic, Rationality and Interaction, Johan van Benthem, Shier Ju and Frank Veltman (eds.), London: College Publications, 85-1, 2007.

Data de Submissão: 09/02/2015

Aprovado para publicação em: 14/02/2016

\begin{tabular}{|c|c|l|l|l|l|}
\hline intuitio & $\begin{array}{c}\text { ISSN } \\
1983-4012\end{array}$ & Porto Alegre & Vol.9- $\mathrm{N}^{\circ} .1$ & $\begin{array}{l}\text { Julho } \\
2016\end{array}$ & p.15-27 \\
\hline
\end{tabular}

